
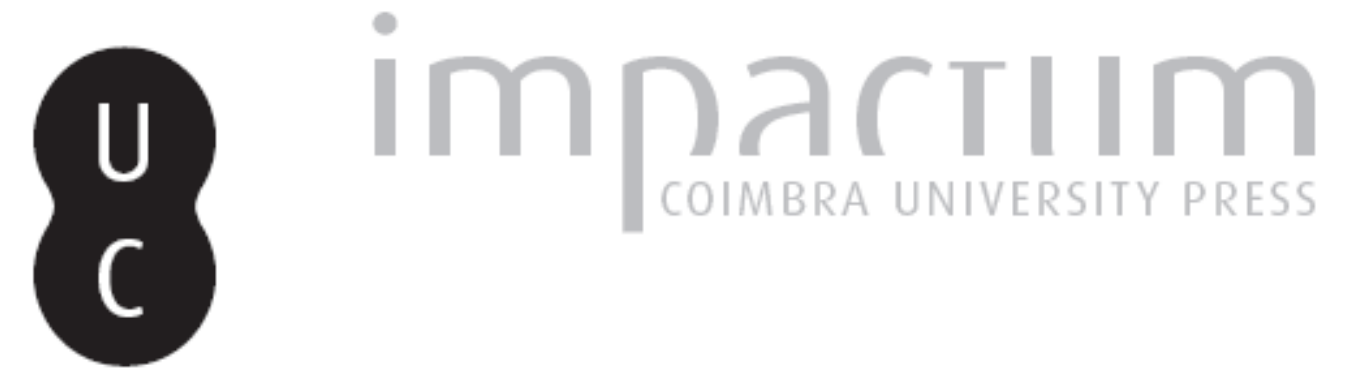

\title{
Elementos de toponomástica lauretana em âmbito lusitano
}

Autor(es): Russo, Mariagrazia

Publicado por: Imprensa da Universidade de Coimbra

URL persistente:

URI:http://hdl.handle.net/10316.2/45636

DOI:

DOI:https://doi.org/10.14195/0870-8584_13_3

Accessed : $\quad$ 26-Apr-2023 03:40:49

A navegação consulta e descarregamento dos títulos inseridos nas Bibliotecas Digitais UC Digitalis, UC Pombalina e UC Impactum, pressupõem a aceitação plena e sem reservas dos Termos e Condições de Uso destas Bibliotecas Digitais, disponíveis em https://digitalis.uc.pt/pt-pt/termos.

Conforme exposto nos referidos Termos e Condições de Uso, o descarregamento de títulos de acesso restrito requer uma licença válida de autorização devendo o utilizador aceder ao(s) documento(s) a partir de um endereço de IP da instituição detentora da supramencionada licença.

Ao utilizador é apenas permitido o descarregamento para uso pessoal, pelo que o emprego do(s) título(s) descarregado(s) para outro fim, designadamente comercial, carece de autorização do respetivo autor ou editor da obra.

Na medida em que todas as obras da UC Digitalis se encontram protegidas pelo Código do Direito de Autor e Direitos Conexos e demais legislação aplicável, toda a cópia, parcial ou total, deste documento, nos casos em que é legalmente admitida, deverá conter ou fazer-se acompanhar por este aviso.

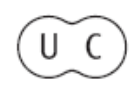




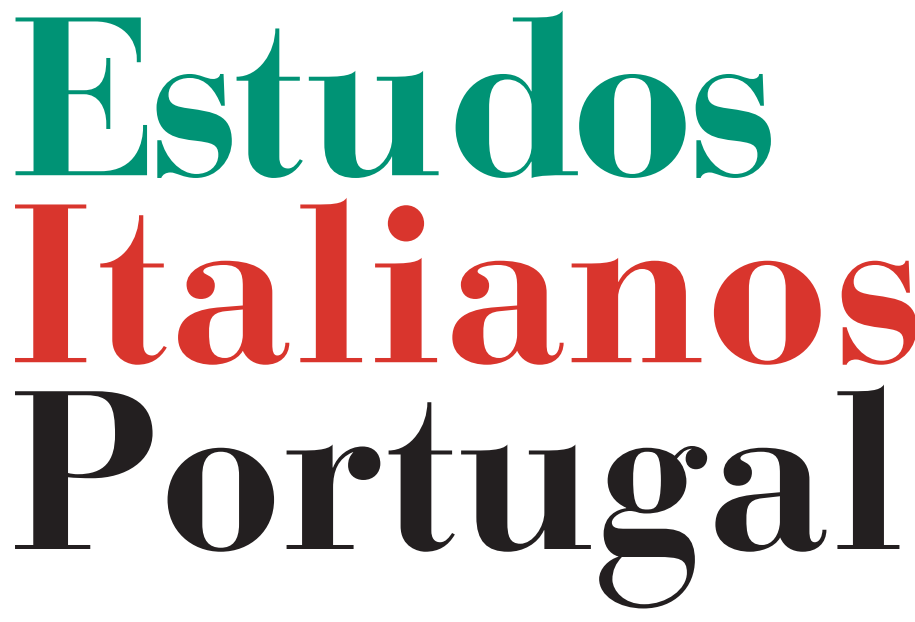

Instituto

Italiano

de Cultura

de Lisboa

Nova Série

$\mathrm{N}^{\mathbf{0}} 13$

2018 


\section{ELEMENTOS DE TOPONOMÁSTICA LAURETANA EM ÂMBITO LUSITANO}

MariagraZia Russo *

Nossa Senhora de Loreto é um importante santuário mariano que surge na pequena cidade de Loreto na província da Itália central chamada Marche. A forma 'loreto' ou 'laureto' (devido à monotongação do ditongo latim AU) deriva do latim LAURETUM, correspondente a um 'loureiral' ou seja a um terreno onde abundava o LAURUM, a planta do louro, o loureiro. A forma LAURUS parece derivar de LAUDUS (com rotacismo da consoante alveolar sonora /d/ em [r]) de LAUDARE, 'louvar' porque a planta era considerada símbolo de glória (nesta planta foi mitologicamente transformada Dafne para fugir dos amores de Apolo). Outras raízes poderiam ser encontradas no sanscrito DÂRU por 'madeira' ou 'pinheiro', derivado por sua vez do radical DRAU, DRU do qual também se origina o antigo eslavo 'drêvo', o grego 'dry' com o significado de 'carvalho', o anglosaxone 'trêo', 'trêow', o inglês 'tree'. A passagem do D- inicial a L-é, de resto, um fenômeno reconhecido em algumas áreas da Península Ibérica: como sugere Joan Corominas "no escasean los ej[emplo]s de una T- o D- latina o romance convertida

* Professora catedrática de Língua e Tradução Portuguesa na Università degli Studi Internazionali di Roma (UNINT) e diretora da Faculdade de Interpretação e Tradução. mariagrazia.russo@unint.eu

${ }^{1}$ Cfr. Ottorino Pianigiani, Vocabolario etimologico della lingua italiana, Società Roma, editrice Dante Alighieri, 1907. 
en $l$ - por los vascos"2. A este respeito, repare-se no que afirma Pedro Augusto Ferreira em relação ao topónimo Doroso, neste contexto de nossa pertinência : "é talvez uma forma de Loroso, por Louroso, contracção de loureiroso, abundante em loureiros"'. De outro lado, entre os celtas o 'lawr' ou 'bla$w r$ ', significava 'verde', aludindo provavelmente à sua folhagem sempre-viva.

O louro, amplamente conhecido na época grego-romana, assumiu com o tempo um signficado simbólico muito amplo, sendo coroado de louro o próprio imperador. Por translato, veio a ter no tempo vários significados até chegar hoje em dia a ser utilizado, por exemplo, na palavra laureado com o significado de 'coroado de louros' e/ou 'falardoado, premiado', assim como o BACCA-LAURATUS passou a indicar em muitas línguas o 'bacharelato', tornando-se a coroa de lauro o marco acadêmico por excelência. O louro aparece, portanto, por um lado como uma das plantas mais conhecidas por todos os países da bacia do Mediterrâneo, sendo difícil determinar a sua área natural de origem, por se ter difundido muito a sua produção em termos botânicos; e por outro uma referência cultural extremamente ligada a valores simbôlicos de ampla tradição incluindo ancestrais aspetos mitológicos, religiosos, de glória e sucesso.

Não é de admirar portanto que em muitas línguas românicas esta planta tenha definido espaços e lugares onde se encontrava particularmente difundida, passando depois a determinar uma toponomástica ainda hoje presente no território. Em Itália topónimos como Laureto, Laurino, Laurito, Lauro, Lauropoli, Lorentino, Loretello, Loreto, Loritto, Loro (provavelmente todos de mesma origem) estão espalha-

${ }^{2}$ Cfr. Joan Corominas, Diccionario crítico etimológico de la lengua castellana, Berna, Editorial Francke, vol. III, 1954, s. v. leme

${ }^{3}$ Pedro Augusto Ferreira, Tentativa etimológico-toponímica ou Investigação da etimologia ou proveniência dos nomes das nossas povoaçôes, 3 vols., Porto, Tipografia Pereira, vol. III, 1907, p. 299 (Porto, Tipografia Mendonça, 1915 e 1917). 
dos por toda a península ${ }^{4}$. Em Portugal os nomes derivados desta planta são centenas a testemunha de que na Península Ibérica eram amplamente difundidos quer este tipo de árvore de folha perene, quer a modalidade de definição dos territórios através da vegetação ${ }^{5}$.

Pedro Augusto Ferreira fornece uma lista aproximativa destes topónimos mas eloquente:

Laureiro, Laurencia Laurenciano, Lordellinho, Lordello, (só com este nome 26 povoações); Lordemão, Loredo, Lo reto, Loridos, Lorosos, Lorvão, Louraes, Loural, Loure, Lou reda, Lourede, Louredinho, Louredo (só com este nome 48 povoaçôes) ; Louredos, Loureira (só com este nome 14 povoaçôes); Loureiro e Loureira (só com estes dois nomes 80 povoações); Lourel, Lourença, Loureucinho, Lourenço, Lourenços, Lourentim, Loures, Louriçal, Louriceira (só com este nome 14 povoaçōes); Louridal, Lourido, Louridos, Louril, Lourim, Lourinha, Lourinhā, Lourinhal, Lourinhos, Louriz, Lourizella, Louro, Louros, Lourosa (15 povoações só com este nome); Lourozella, Louroso, Luriz e Luro, diapasão francez de Louriz e Louro. Só com os nomes de Lordello, Louredo, Loureira, Loureiro e Loureiros, - Louriceira e Lourosa - 197 povoaçôes e ao todo talvez mais de $300^{6}$.

Sem nenhuma pretensão de exaustividade, queremos neste contexto propor um percurso que nos leve a definir em termos quer diacrónicos quer diatópicos a toponímia portuguesa ligada a esta planta, cuja presença deu origem em Itália ao topónimo de interesse mariano.

${ }^{4}$ A toponomástica na área catalã foi aprofundada por Antoni Ginard Bujosa e Andreu Ramis Puig-Gros, Sobre el topònim Loreto - Llorito alsa paises catalans, in Congrés Internacional de toponimia i Onomástica Catalanes, València, Universitat de València, 2001, pp. 949-963.

${ }^{5}$ Para Portugal cfr. José Joaquim Nunes, “A vegetação na toponímia portuguesa”, Boletim da Classe de Letras, vol. XIII, 1921, pp. 131-175; José Pinto Loureiro, Toponimia de Coimbra, Edição da Câmara Municipal, Coimbra, 1964.

${ }^{6}$ P. A. Ferreira, cit, vol. III, pp. 499-500. 
Em Portugal o primeiro documento em latim vulgar que remonta ao ano de 882 é a conhecida escritura em favor da igreja de Lordosa: "Christus. In nomine Patri et Filii et Spiritus Sancti Domnis inuictissimis ac triumphatoribus sanctis martiris Petri et Pauli, Sancti Migaeli Arcamgeli, cuius baselica fundamus in uilla quod uociant Lauridosa". Neste documento os dois assignatários "Muzara et Zamora" entregam, além de móveis e alfaias, alguns terrenos aos padres da igreja de S. Pedro, S. Paulo e S. Miguel Arcanjo, para o cemitério na povoação de Lordosa no conecelho de Penafiel, antigo território de Anégia. O étimo de Lordosa, derivado de LAURITOSA, no qual entram os sufixos adjetivais -ITUM, correspondente a -ETUM, e -OSA, assenta no latino LAURU-. Portanto, o mais antigo documento latino-português originl de que se conheça a existência ${ }^{7}$, conservado no Instituto dos Arquivos Nacionais / Torre do Tombo (Mosteiro de S. Pedro de Cete, PT-TT-MSPC/1/1, Ordem de São Bento, Mosteiro de S. Pedro de Cete, mç 1, doc. 1), cita o topónimo de nosso interesse, a demonstração de que a forma de definição deste espaço através de uma planta autóctona podia ser bastante frequente. A actual Igreja de Lardosa (assim como evoluiu a forma ao longo do tempo para indicar uma terra de loureiros), que teve origem na Ordem de São Bento e no Mosteiro de São Pedro de Cete, em Paredes no concelho de Penafiel, foi portanto fundada no ano de 882 . Os topónimos hoje assim definidos (Lardosa) são três: além deste lugar da freguesia de Rans, no concelho de Penafiel, uma freguesia do concelho de Castelo Branco de origem romana, e un lugar na freguesia de Soalhães, no concelho de Marco de Canaveses, que se

${ }^{7}$ PORTVGALIAE MONVMENTA HISTORICA a Saeculo Octavo post Christum usque ad Quintum Decimum. Dipoomata et Chartae, Lisboa, Academia das Ciências, 1867, vol. I, p. 6, doc. IX; Rui de Azevedo, "O mais antigo documento Latino-Português”, Arquivo Histórico de Portugal, I, 1932, 189-191; e o estudo de António Emiliano, "O mais antigo documento latino português (882 a. D.), edição e estudo grafémico", Verba. Anuário Galego de Filoloxia, 26, 1999, 2000, pp. 7-42. 
destaca pela sua ribeira de Lardosa, onde foi encontrada uma sepultura pré-histórica que remonta ao III milénio a. C.

Além destes lugares existe um topónimo que guarda a forma original de Lordosa na província de Viseu; assim como numerosos Lourosa (3 freguesias de concelhos: da Feira; de Viseu; e de Oliveira do Hospital; e 6 lugares de freguesia: de Esperança, concelho da Póvoa de Lanhoso; de Macieira, concelho de Cinfães; de Santa Cruz da Trapa, concelho de São Pedro do Sul; de Santiago de Besteiros, concelho de Tondela; de Tremês, concelho de Santarém; aos quais se juntam Lourosa de Campos, um lugar da freguesia de Burgo, concelho de Arouca; e Lourosa de Matos, um lugar da freguesia de Urrô, concelho de Arouca ${ }^{8}$ ). Deste topónimo são formas diminutivas os lugares denominados Lourizela (da freguesia de Esteves, concelho de Sever de Vouga, e da freguesia de Préstimo, concelho de Águeda) e Lourosela (lugar da freguesia de S. Julião, concelho de Valença).

À volta dessa planta autôctona formaram-se outros topónimos, os primeiros dos quais derivantes do próprio LAURUM: Louro (freguesia do concelho de Vila nova de Famalicão) e Loure (Lugar da Freguesia de S. João de Loure, concelho de Albergaria-a-Velha); assim como as formas plurais Louros (lugar da freguesia de Airão, concelho de Guimarães) e Loures (Vila, sede de concelho e de freguesia, distrito, comarca e patriarcado de Lisboa). Em ambos os topónimos (na forma singular como na plural) assiste-se à concorrência da saída em -e, bastante frequente na onomástica portuguesa.

Derivada dos campos de louro é também a forma LAURETUM da qual deriva diretamente o topónimo de Loreto. Remonta ao ano de 1009 um documento onde se assinala a presença de uma uilla loureto: "Ereditate nostra propria que auemus in uilla loureto discurrentis ribolum leza", cuja re-

${ }^{8}$ Para o presente trabalho foram consultados diferentes dicionários corográficos e enciclopédias: um para todos A. C. Amaral-Frazão, Novo dicionário corográfico de Portugal, Porto, Editorial Domingos Barreira, [s.d.], s. v. 
ferência é dada por José Pedro Machado'. A mesma expressão recorre no Cartório do Mosteiro de Moreira, da época de Afonso V (1432-1481; 1438), publicado por João Pedro Ribeiro nas Dissertaçôes Chronologicas e Criticas sobre a historia e jurisprudencia ecclesiastica e civil de Portugal ${ }^{10}$ : "uilla laureto discurrentis ribolum leza" (documento datado de 1047). No Inventario das terras de Guimarães, presente num documento del 1059, inserido no Livro de D. Mummadona (CCCCXX), entre as vilas citadas aparece a "villa laureda" e "lauredo". São numerosos os topónimos derivados da forma LAURETUM, que hoje em dia marcam a presença desta planta aromática em território português. Assinalam-se assim os seguintes Louredo: 6 freguesias (dos concelhos da Póvoa de Lanhoso; de Santa Marta de Penaguião; de Vieira do Minho; de Paredes, também designada por Louredo da Serra; da Feira; de Amarante) e 16 lugares de freguesias (de Abragão, concelho de Penafiel; de Calendário, concelho de Vila Nova de Famalicão; de Campelo, concelho de Baião; de Cervães, concelho de Vila Verde; de Coronado, concelho de Santo Tirso; de Guilhofrei, concelho de Vieira do Minho; do Luso, concelho de Mealhada; de Moreira de Geraz do Lima, concelho de Viana do Castelo; de Paranhos, concelho de Amares; da freguesia e concelho de Penafiel; da freguesia e concelho de Vila Nova de Poiares; de Revelhe, concelho de Fafe; da Ribeira, concelho de Terras do Bouro; de São Cipriano, concelho de Resende; de São Cristóvão de Nogueira, concelho de Cinfães; de Selho, concelho de Guimarães). Além destes topónimos existem também outros lugares com mais elementos acrescentados ao próprio topónimo em exame: Louredo das Almas (da freguesia de Salvador do Monte, concelho de Amarante), Louredo de Além (da freguesia de Vilaça, concelho de Braga), dois Louredo de Baixo (um lugar da freguesia

${ }^{9}$ Dicionário etimológico da língua portuguesa, Lisboa, Livros Horizonte, 1952, s. v. Louredo.

${ }^{10}$ Lisboa, Tipografia da mesma Academia, 1810, t. I, p. 203. 
de Miomães, concelho de Resende; e um lugar da freguesia de Salvador do Monte, do concelho de Amarante), Louredo de Cima (da freguesia de Miomães, concelho de Resende), Louredo de Matos (da freguesia de S. Cristóvão de Nogueira, concelho de Cinfães) e por fim Louredo do Meio (da freguesia de Vilaça, concelho de Braga). A forma concorrente Lourido è presente no território português com 9 lugares de freguesias (Alvarenga, concelho de Arouca; Arnóia, concelho de Celorico de Basto; Entre Ambos-os-Rios, concelho de Ponte de Barca; Escudeiros, concelho da Feira; Godinhaços, concelho de Vila Verde; Golães, concelho de Fafe; Jugueiros, concelho de Felgueiras; Vale, concelho de Paredes de Coura). Existem também topónimos que mantêm a forma originária feminina da planta: Laureda (freguesia do concelho de Arcos de Valdevez), Loureda (freguesia do concelho de Arcos de Valdevez) e uma forma diminutiva de um lugar da freguesia do Vale do concelho da Feira: Louredinho.

Nascem de formas adjetivais (ligadas ao terreno e à sua abundante produção de louro) também os topónimos Lourim (lugar da freguesia e concelho da Lourinhã), Lourinha (lugares das freguesias respetivamente de Formariz, concelho de Paredes de Coura; de Rio Tinto, concelho de Gondomar; de Ronfe, concelho de Guimarães; de Vila Nova de Ourém) às vezes definidas com outros elementos descritivos a indicar a posição (ambos os lugares do concelho de Mortágua): Lourinha de Baixo (da freguesia de Marmeleira) e Lourinha de Cima (da freguesia de Cortegaça). Também não se distancia deste étimo o topónimo Lourinhã (distrito de Lisboa), cuja existência remonta aos tempos dos Romanos que a denominaram, assim como sugere Serafim da Silva Neto" "VILLA LAURINIANA, isto è, DE LAURINUS ou LAURINIUS, a que hoje corresponde a freguesia de Lourinhâ", embora neste último caso seja considerada como pertencente a um pos-

\footnotetext{
${ }^{11}$ Serafim da Silva Neto, História da língua portuguesa, Rio de Janeiro, Presença, 1986 (4 edição), p. 90.
} 
suidor. Pode remontar a possuidores a forma $-i z$ derivada de -ICI germânico no topónimo Louriz (lugar da freguesia de Sobrado, concelho de Castelo de Paiva e lugar da freguesia de Alpendurada e Matos, concelho de Marco de Canaveses) e a variedade Luriz (lugar da freguesia do Campo, concelho de Valongo) pelo qual Pedro Augusto Ferreira ${ }^{12}$ afirmava tratarse de "diapasão francez".

Profícuo parece ter sido também o topónimo derivado da forma LAURARIUM (quer no masculino quer no feminino): é do ano 1029 um texto latino transcrito no $\mathrm{Di}$ plomata et Chartae no qual aparece uma "uila quos uocitant laureiro"13. Hoje em dia encontramos o topónimo Loureira (que mantém a antiga origem feminina da árvore) atribuído a uma freguesia do concelho de Vila Verde, e a 5 lugares, nomeadamente das freguesias de Abiul, concelho de Pombal; de Ançã, concelho de Cantanhede; de Puços, concelho de Alvaiázere; de Santa Catarina da Serra, concelho de Leiria; de São Pedro, concelho de Porto de Mós.

Da forma masculina Loureiro aparecem 2 freguesias (dos concelhos de Oliveira de Azeméis, e de Peso de Régua) e 29 lugares de freguesia (de Afife, concelho de Viana do Castelo; de Areias de Vilar, concelho de Barcelos; de Árvore, concelho de Vila do Conde; de Calhandriz, concelho de Vila Frana de Xira; de Castelo, concelho de Alijó; de Cernache, concelho de Coimbra; de Correlhã, concelho de Tábua; de Delães, concelho de Vila Nova de Famalicão; de Eira Vedra, concelho de Vieira do Minho; de Esporões, concelho de Paços de Ferreira; de Figueiró da Serra, concelho de Gouveia; de Gémeos, concelho de Celorico de Basto; de Insalde, concelho de Paredes de Coura; de Lustosa, concelho de Lousada; de Paços de Gaiolo, concelho de Marco de Canaveses;

\footnotetext{
${ }^{12}$ P. A. Ferreira, cit., vol. III, p. 264.

${ }^{13}$ PORTVGALIAE MONVMENTA HISTORICA a Saeculo Octavo post Christum usque ad Quintum Decimum. Diplomata et Chartae, Lisboa, Academia das Ciências, 1867, vol. I, p. 163.
} 
de Padreiro, concelho de Arcos de Valdevez; de Perosinho, concelho de Vila Nova de Gaia; de Pinheiros, concelho de Monção; de Raiva, concelho de Castelo de Paiva; de Rebordões, concelho de Fafe; freguesia e concelho de Resende; de Sande, concelho de Marco de Canaveses; de São Félix, concelho de S. Pedro do Sul; de Silvalde, concelho de Espinho; de Sobreposta, concelho de Braga; de Sul, concelho de S. Pedro do Sul; de Torno, concelho de Felgueiras; de Vila Chã, concelho de Ponte da Barca; de Vizela, concelho de Guimarães). Além disso existem também topónimos complexos que enriquecem o topónimo principal: Bouça Loureiro (lugar da freguesia e concelho de Resende), onde o topónimo Loureiro encontra-se com a definição de um terreno em que se cria mato para roçar; Casal do Loureiro (um lugar da freguesia de Gradil, concelho de Mafra; e um lugar da freguesia de Santiago da Guarda, concelho de Ansião); Casal Loureiro (sem a preposição no meio a dividir os dois elementos, lugar da freguesia e concelho de Góis); Loureiro de Baixo e Loureiro de Cima (ambos lugares da freguesia de Grijó, concelho de Vila Nova de Gaia), Loureiro de Silgueiros (uma freguesia do concelho de Viseu); Quinta do Loureiro (2 lugares um da freguesia de Cacia, concelho de Aveiro e outro da freguesia e do concelho de Ferreira de Zêzere).

A forma plural Loureiros identifica de maneira ainda mais marcada uma abundância da difusão da planta. Existem 6 lugares de freguesia: em Ansião; em Carvide, concelho de Leiria; em Meães do Campo, concelho de Montemor-o-Velho; em Quiaios, concelho da Figueira da Foz; em Silvalde, concelho de Espinho; em Santa Maria e São Miguel, concelho de Sintra.

Do baixo latim LAURITELLUM, usado como diminutivo para identificar um pequeno bosque de loureiros, derivam numerosas localidades designadas Lordelo: 6 freguesias de concelho (de Vila Real; de Felgueiras; de Guimarães; de Monção; de Paredes; de Ancede) e 13 lugares de freguesia 
(Ancede, concelho de Baião; Arnoso, concelho de Vila Nova de Famalicão; Boivão, concelho de Valença; Bouro, concelho de Amares; Cabreiro, concelho de Arcos de Valdevez; Paredes, concelho de Penafiel; Ribas, concelho de Celorico de Basto; Sanguedo, concelho da Feira; Serafão, concelho de Fafe; Sousa, concelho de Felgueiras - citado nas Inquirições de D. Dinis de 1287 -; Veade, concelho de Celorico de Basto; Vila Chã, concelho de Vale de Cambra; de Vila Seca, concelho de Barcelos). Além disso existe um idronímico Rio Lordelo afluente do Vouga, num lugar definido Lordelo de Baixo (freguesia de Lara, concelho de Monção) e uma freguesia Lordelo do Ouro (do segundo Bairro do Porto).

Derivam do mesmo étimo latino LAURARIUS os topónimos Loural, com o seu plural Lourais, Lourel e Lourinhal. Do primeiro existem 4 lugares de freguesias (de Arranhó, concelho de Arruda dos Vinhos; de Louriçal do Campo, concelho de Castelo Branco; de Monte Redondo, concelho de Leiria; de Santa Lucrécia de Algeriz, concelho de Braga); do segundo há 2 lugares de freguesia (Gandra, concelho de Ponte de Lima; Colmeias, concelho de Leiria); do terceiro encontramos um lugar (freguesia de Santa Maria e S. Miguel, concelho de Sintra); e do último achamos dois lugares (um na freguesia de Carvalho, concelho de Penacova; outro na freguesia de S. Martinho da Gândara, concelho de Oliveira de Azeméis).

A forma Louriçal persiste na toponomástica como freguesia do concelho de Pombal e como lugar da freguesia do concelho de Alcanena e da freguesia de Aboboreira, concelho de Mação. A esta pode-se acrescentar Louriçal do Campo, freguesia do concelho de Castelo Branco. Ao lado deste topónimo vive a forma Louriceira, onde o sufixo -eiro/-eira indica a árvore ou o cultivo (veja-se por exemplo a formação de palavras como videira, pessegueiro, etc.): encontramos uma freguesia (do concelho de Alcanena) e 7 lugares de freguesias (de Aboboreira, concelho de Mação; de Almoster, concelho 
de Santarém; de Cernache de Bomjardim, concelho da Sertã; da Cumieira, concelho de Penela; de Igreja Nova, concelho de Pedrogão Grande; de Pias, concelho de Ferreirado Zêzere; de São Pedro e Santiago, concelho de Torres Vedras), existindo também 2 lugares Louriceira de Baixo (um na freguesia de Arranhó, concelho de Arruda dos Vinhos, e outro na freguesia de Santiago da Guarda, concelho de Ansão); e um lugar Louriceira de Cima (da freguesia de Arranhó, concelho de Arruda dos Vinhos).

Os topónimos representam para qualquer cultura os elementos linguísticos mais ancestrais, vestígia de uma presença que o tempo dificilmene apaga. As definições dos territórios, marcados por caraterísticas do solo ou por peculiaridades que o próprio solo tem, resistem ao passar dos séculos de maneira que as cristalizaçôes das formas acabam por não permitir uma imediata associação entre a origem e a realidade presente. Os topónimos analizados refletem uma parte deste percurso linguístico. $\mathrm{O}$ elemento até aqui analizado que produziu tanta variedade toponomástica em Portugal também é presente em território italiano como no espanhol: uma 'mediterraneidade' que foi ligando povos, culturas e espaços geográficos. Desta forma, o nome de um topónimo presente em Itália encontrou-se evoluído com modalidades diferentes em Portugal, mantendo a semântica da demarcação territorial. Nesta definição do espaço intervém outro elemento ligado a uma forte conotação cultural religiosa capaz de tornar um topónimo bastante vulgar em lugar único por valor simbólico. Ao mito apolíneo vai-se assim sobrepôr o culto mariano, entrelaçando imagens que vão reforçar o valor originário do próprio nome: Loreto, ligado a uma planta simbolicamente gloriosa, desta forma, esalta-se ainda mais sob a presença da devoção ligada à Nossa Senhora. Desta maneira, se por um lado os topónimos que nasceram à volta de LAURETUM definem espaços marcados pela difusão da própria planta, por outro há de se constatar que dois topónimos aparecem 
hoje com o nome de Loreto na forma perfeitamente correspondente ao topónimo italiano sem a sonorização do -Tintervocálico, ambos sem dúvida ligados ao culto da Nossa Senhora: um lugar da freguesia de Cristelos, no concelho de Lousada, no distrito do Porto, onde não faltam âmbitos que lembrem a Nossa Senhora do Loreto, como avenida, praça, rua e capela intituladas à Virgem, amplamente celebrada; e um lugar na freguesia de Eiras, no concelho de Coimbra (na estrada Loreto) também definido Bairro de/do Loreto ou Urbanização Loreto onde a Capela da Nossa Senhora da Guia ou da Nossa Senhora de Loreto, construída em 1596, liga este espaço ao culto mariano, mais do que a uma produção agrícula do terreno. A distância de poucas décadas da construção da igreja de Loreto em Lisboa, que remonta a 1518, o culto mariano chegou rapidamente a Portugal, marcando de outra maneira um topónimo que no próprio território português já tinha tido a sua própria evolução. Podemos então comprovar que, enquanto os outros topónimos relacionados com a planta do LAURUM evoluíram numa ampla variedade de formas, o topónimo Loreto, entrado só no século XVI desde Itália, permanece por enquanto ligado exclusivamente ao culto mariano. 